\title{
Investigation of the influence of polyelectrolytes hydrodynamic properties on the hydrate formation process
}

\author{
Volodymyr Bondarenko ${ }^{1}$, Olena Svietkina ${ }^{2}$, Kateryna $\mathrm{Sai}^{1^{*}}$, and Vasyl Klymenko ${ }^{3}$ \\ ${ }^{1}$ National Mining University, Department of Underground Mining, 19 Yavornytskoho Ave., \\ 49005 Dnipro, Ukraine \\ ${ }^{2}$ National Mining University, Department of Chemistry, 19 Yavornytskoho Ave., 49005 Dnipro, \\ Ukraine \\ ${ }^{3}$ Central Ukrainian National Technical University, Department of Electrotechnical Systems and \\ Energy Management, 8 Universytetskyi Ave., 25006 Kropyvnytskyi, Ukraine
}

\begin{abstract}
One of the most perspective non-traditional sources of hydrocarbon raw materials and energy is gas hydrates $(\mathrm{GH})$, which stimulates their large-scale study in many laboratories and scientific centers around the world. The interest in the GH is related to the possibility of their industrial application. The use of technologies for storage and transportation of natural gas in the form of GH requires fundamental kinetic studies of the hydration process at atmospheric pressure in the presence of chemical impurities (catalysts, surfactants, etc.). During the research, an increase in the rate of gas hydrates formation was discovered at the expense of activated impurities and composite compounds obtained on their basis, which lead to changes in the hydrochemical and hydrodynamical modes of systems. It was established that the process of $\mathrm{GH}$ formation occurs due to the binding of methane macromolecules and other chemical impurities, which contribute to increase the number of moles of gaseous methane, due to the flow of exchange processes between the polymer matrix and water soluble salts, as well as a result of the change in the hydrodynamics of the water system. The purpose of this work is to investigate the effect of polyelectrolytes solutions hydrodynamic properties on the GH formation. We used a number of ionenes based on polymeric quaternary ammonium salts, side aliphatic radicals of different lengths contained in the acyl fragment.
\end{abstract}

\section{Introduction}

The unconventional methods of recovering and obtaining various energy sources are of great interest in recent years, and are directly related to the annual increase in consumption of fuel and energy resources. For this very reason the intensification of geological and prospecting works of all types of energy raw materials is certainly of high priority in Ukraine. One of the alternatives to increasing energy consumption is the search and

\footnotetext{
* Corresponding author: kateryna.sai@gmail.com
} 
evaluation for unconventional hydrocarbon deposits [1 - 3].

The coal industry of Ukraine providing the extraction and primary processing of hard and brown coal, is one of the main branches of the Ukrainian fuel industry. However, the majority of coal reserves are in difficult mining and geological conditions (low thickness of coal seams, great depths of extracting, low rocks stability, increased water-inflow coefficient, seams high gas content) [4]. It forces one to create new strategies for energy development of the country.

The problem of rational use of the existing potential of hydrocarbon gases, in particular methane, remains relevant both as for coal, oil and gas industries, so for petrochemical industry [5-7]. This is particularly true for the transportation and storage technologies of natural gas resources [8], coalmine methane [9], methane of drainage boreholes [10], gas of marginal field and marine field [11], and oil-associated gas.

The introduction of gas hydrate technologies based on the ability of gas and water molecules to form stable clathrate structures, which will provide the possibility of obtaining an additional energy source, is a promising direction in solution of this problem. However, the hydrate formation process, which is the key one, requires intensive binding of significant gas volumes into the gas-hydrate form. Its efficiency determines the economic performance of the technology and the quality of the final product.

Gas hydrate technologies, in comparison with the existing ones, also provide an opportunity with greater energy efficiency to separate mixtures of gases and liquids, compress gases to high pressures, concentrate aquatic solutions, produce and accumulate cold, utilize and store up the carbon dioxide. To study them is also important for solving the problems of methane gas hydrates deposits development, in particular, in the Black Sea water area $[12,13]$.

From the fundamental point of view, gas hydrates are interesting for that they are objects of supramolecular (permolecular) chemistry - a relatively new science that studies the other, subtler principle of chemical matter organization, based not so much on a specific chemical binding as on the favourable spatial complementarity of the reactants, even in the case of only weak van der Waals interactions between them. The physical, physical and mechanical, thermodynamic and electromagnetic properties of gas hydrates, as a solid, are similar to ice, and the study of cryogenic systems has always been an important aspect both for the conditions of life advent and existence, and in order to control the speed and mechanisms of biological processes [14]. The study of the molecules interaction patterns in gas hydrate systems and the structure of the compounds formed, their thermodynamic stability zones (phase diagrams), the kinetics of formation and decomposition is of great importance for many branches of industry and science.

Generally, all hydrophobous gases and highly volatile liquids with molecular sizes of $3.8-9.2 \AA$, and also some hydrophilic compounds having a sufficiently weak interaction with water, which does not prevent clathrate formation, are capable of GH formation [15]. The existing and developed Heriot-Watt Hydrate model (HWHYD) does not consider the mechanism of stable GH compounds formation with almost any hydrophobous gases and highly volatile liquids having molecular dimensions indicated above. Without solving these issues, the technological problems related to gas hydrate systems cannot be solved successfully.

From a practical point of view, the research results are necessary to improve modern technologies for gas production, transportation and storage, as well as to improve the safety of mining operations, and develop new technologies for the integrated development of coal deposits [16]. It can be stated that the study of the GH formation mechanism seems to be one of the most important and urgent problems.

Based on research conducted in the innovative technologies laboratory of National Mining University (National Technical University "Dnipro Polytechnic"), it was found out 
that all the solutions of surface-active materials (surfactants) reduce the surface tension of the solution by $79-96 \%$, although the hydrate formation rate is significantly changed. Thus, it was concluded that the solubilization, passing at the nanoscale level, is the mechanism of hydrate formation. For these nonionic surface-active materials (nonionic surfactants), a feature has been found related to the existence of two zones available for the solubilizate - a hydrophobous hydrocarbon core and a thick (polymolecular) hydrophilic polyoxyethylene capsule, wherein the solubilizate can dissolve both in the core and in the hydrophilic outer micelles capsule. Consequently, it is distributed in equilibrium between these two zones, while the extremely hydrophobous paraffin hydrocarbons, in particular methane, are localized when solubilizing only in the hydrocarbon core of the micelles. The studies of X-ray diffraction in concentrated solutions of surfactants containing solubilizate have shown that when hydrocarbons are dissolved, there occurs the introduction of solubilizate molecules into the intramicellar space between the hydrocarbon-terminated molecules of surfactants.

The peculiarity of this mechanism is that as a result of the surfactants application, the inverse microgas emulsions are formed [17]. This process is shown schematically in Fig. 1.

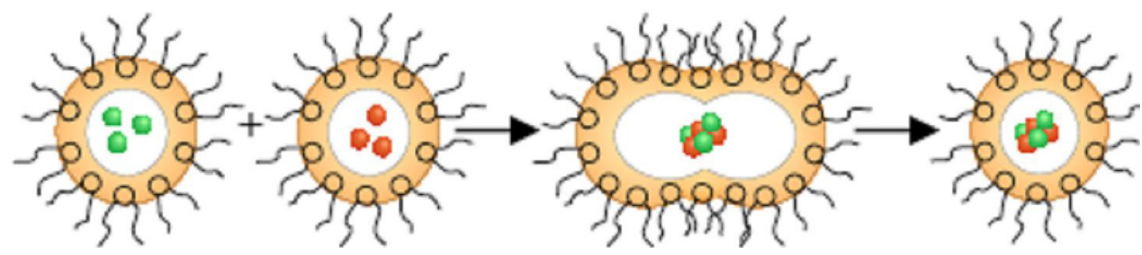

Fig. 1. Scheme of formation of surfactants microgas emulsions: green - water; red - gaseous methane.

Such microgas emulsions, according to Plato, arise when foaming the system "methane + surfactant + water". In the zone of three films contact that belong to three or more contiguous bubbles, a Plato channel is formed. Herein, the methane bubbles in GH have the shape of pentagonal dodecahedron. It is necessary to consider the fact that, at concentrations of $10^{-4}-10^{-2} \mathrm{~mol} / \mathrm{l}$ at a temperature of $274 \mathrm{~K}$, gaseous methane is concentrated inside the pentagonal dodecahedron. This occurs as a result of cryoprotectant properties of surfactants at the indicated temperatures. The resulting micelles are actually the inverse, concentrating the gaseous methane.

\section{Literature data analysis and formulation of the problem}

The process of the GH formation is in the formation of a new phase (solid). The uncontrolled processes proceeding are caused by the fact that the new state of the system under the changed conditions is more stable and has a lower energy reserve. The formation of interphase surfaces and associated surface phenomena is due to excess surface energy. This is due to the fact that the molecules of the gaseous phase (methane) are in the interphase surface, have excess energy in comparison with the molecules in the volume because of their uncompensated intermolecular interactions. The resulting uncompensated intermolecular interactions are caused by the difference in the composition and structure of the contacting phases, and this leads to the occurrence of surface forces and an excess of energy - surface energy, on the interphase surface.

Transportation and use of GH consists of three phases: hydrate formation; transportation by itself; gas release in its decomposition. The first stage is the mixing of gas with water under the necessary conditions. One of the serious problems is the low rate of hydrate formation, which slows down the industrial application of this method. To solve this 
problem, surfactants and hydrotropes are often used [18], which makes it possible to find out the fine details of the mechanism of the hydrate formation process and its kinetics. Nevertheless, when adding surfactants, a side effect is often observed, which leads to a decrease in the methane hydrate stability. As it is shown in the work of [19], this can be avoided by adding a mixture of sodium dodecyl sulfate, xanthan, or starch.

The problem of the hydrate formation process acceleration is being studied by scientists from India, Iran, Canada, the USA, and Beijing. Thus, Iranian researchers studied the effect of copper oxide nanoparticles usage in order to increase the volume of gas absorbed by water to better convert water to a hydrate state and to increase the kinetics of the hydrate formation process [20]. The United States scientists have developed a technology for spraying water through the gas phase to increase the contact area of the hydrogen and gas phases, which leads to the hydrate formation process acceleration [21]. Indian scientists have proposed the use of surfactants to accelerate the process of hydrates nucleation, to provide for more active heat transfer and to increase the water and gas contact surface [22].

The first group in the field of studying the processes of hydrate formation in electrolytes solutions under laboratory conditions was the Canadian group of Professor P.R. Bishnoi [23]. These studies were carried out in a stirred-tank reactor in solutions of $\mathrm{NaCl}$ and $\mathrm{KCl}$ with different mineralization (up to $8 \mathrm{wt} . \%$ ), in a narrow temperature range $(270-274 \mathrm{~K}$ ) at a fixed stirrer speed of $400 \mathrm{rpm}$. In this work, the diffusive mechanism of the hydrate formation process is considered. It is assumed that on the surface of the hydrate particles formed there is a water film through which the gas diffuses to the hydrate surface.

In works of $[24,25]$, the natural gas hydrates synthesized in sodium and calcium chlorides solutions were the objects of the study. The concentrations of sodium chloride solutions were 5,10 and $15 \%$, which corresponds to the total mineralization of salt brines 51.8; 107.1 and 166.3 grams per litre. It was identified that the chemical nature of salts affects the formation and decomposition processes, as well as the texture of natural gas hydrates [26, 27]. The hydrates formation in sodium chloride solutions proceeds more slowly than in calcium chloride solutions. With increase in mineralization of solutions, the rate of gas hydrates decomposition increases.

The kinetics of hydrate formation of carbon dioxide and gas mixtures containing carbon dioxide in sodium chloride solutions, was studied by the Beijing group of Professor T.M. Guo [28]. The experiments were also carried out in a stirred-tank reactor.

The work of [29] describes the kinetic curves of methane hydrate formation in distilled water and water containing inhibitors (concentration of salts - up to $5 \mathrm{wt} . \%$ ). In accordance with the traditional concepts of formal kinetics, a process proceeding mechanism has been proposed, which includes the stages of gas dissolution, a metastable hydrate cluster formation and a gas hydrate particle growth. The potential reversibility of each process stage was taken into account, and a general kinetic equation was suggested. The pressure of the gas-hydrating agent was not maintained during the process. The absorption rate of methane was calculated according the pressure drop in the experimental cell.

Thus, the results of fundamental studies of the GH formation mechanism, as well as data on the chemical additives and surfactants which influence on the hydrate formation rate, can significantly affect the technological and economic attractiveness of natural gas storage in the gas hydrate form.

A new direction in the $\mathrm{GH}$ formation is their production in the presence of polyelectrolytes (PE), which are widely used in various industries as flocculants and coagulants of disperse systems, for example, for clarification of waste and turbid waters, for structuring of soils and grounds from radioactive elements [30], as well as for the colloids stabilization, in particular, for emulsions and foams, which is especially important in the obtaining GH. Besides, it is known that PE make an effect on the hydrodynamic properties of ecosystems [31]. The polymer dissolution in the liquid is accompanied not only by an 
increase in the viscosity, but also by an increase in the rate of the turbulent flow of the polymer solution in comparison with the flow rate of the initial low-viscous dissolvent. This paradox (Toms effect), which was discovered in the middle of the last century, up to the present time does not have a generally accepted theoretical basis. The first who engaged in a detailed study of the effect of the hydrodynamic drag reduce were hydromechanics who considered macromolecules of different chemical nature only as mathematical objects devoid of individual physical and chemical properties. This made possible to present a formal quantitative description of the phenomenon, but such a mechanistic approach is one of the reasons for the lack of the Toms effect explanation [32].

\section{Materials and methods of research of hydrodynamic regimes influence on hydrate formation process}

\subsection{The essence of conducted research}

The stalagmometric method with automatic photoelectron count of drops (measurement error $0.1 \%$ ) was used. To determine the critical concentration of micelle formation (CMC), a conductometric method was used (conductivity meter No. 5721, Wroclaw: ElVRO). The electrical conductivity was measured with a Wheatstone bridge (measurement error $0.05-0.1 \%$ ).

Interphase electric potential was measured by the potentiometric method using the PPTV1 potentiometer.

The number average molecular weight of the polyelectrolyte samples was determined by spectrophotometric titration of amine-terminated groups 0.01 with $\mathrm{HCl}$ alcoholic solution in triphenyl-verdazil presence, and was also evaluated from the reduced viscosity of aqueous solutions of ionenes at a concentration of $0.1 \mathrm{~g} / \mathrm{dl}$. The measurements of the PE solutions viscosity were carried out on a VPJ-1 viscometer with a capillary diameter of $0.54 \mathrm{~mm}$ after temperature equilibrium was set at $25+0.1{ }^{\circ} \mathrm{C}$.

\subsection{Experimental studies of the rate of gas hydrates formation}

The research on the study of the GH formation mechanism in the presence of surfactants was carried out in an installation created in the innovative technologies laboratory of National Mining University (National Technical University "Dnipro Polytechnic") [33, 17]. The laboratory facility makes it possible to conduct the research of high-speed methane GH production under mild conditions (at pressures up to $7 \mathrm{MPa}$ ) and temperatures from 274 to $281 \mathrm{~K}$.

The methods of experiments for obtaining methane $\mathrm{GH}$ in the presence of surfactants in laboratory conditions is described in the work of [34]. The rate of methane hydrate formation was determined by the kinetic method from the initial rate of the ice crust formation, and then the amount of methane per unit volume $\left(C_{m}\right)$ was determined at different surfactant contents.

The methodology for determining the amount of methane per unit GH volume obtained at different surfactant content, as described in detail in work [34], include the following main stages:

1. Temperature decrease in the climatic thermal chamber and, accordingly, in the hydrate formation reactor from 274 to $263-258 \mathrm{~K}$ after the end of the GH production process, when all the water reacted with the gas;

2. Closing of valves on the cylinder with gas and on the reducer;

3. Disconnecting the high-pressure hose from the reducer and connecting it to the gas meter; 
4. Opening the reactor valve and temperature rise to room temperature in the chamber and in the reactor;

5. Decomposition of methane hydrate and passing the released gas through the gas meter to determine its amount.

Knowing the value of the extracted methane and the volume of water poured into the reactor, the value of $C_{m}$ was determined. Then the gas pressure in the reactor was reduced by $1 \mathrm{MPa}$ and the determinations were repeated.

\section{The results of experimental studies of the gas hydrates formation mechanism in the presence of polyelectrolytes}

The hydrodynamic properties of PE are largely determined by intra- and intermolecular electrostatic interaction of charged sections of the chain, which leads to the formation of unfolded conformations [35]. On the other hand, the presence of hydrophobous groups, the possibility of forming intramolecular salt bridges and hydrogen bonds leads to the compact structures formation. In general, the conformational state of the PE macromolecule is determined by the ratio of forces of electrostatic and non-electrostatic interactions, which can be estimated from the values of the characteristic viscosities. A sharp increase in the reduced viscosity in the area of low polymer concentrations does not make it possible to determine the characteristic viscosity by extrapolation to zero concentration, and therefore the viscosimetrical data were linearized in the coordinates of the equations in the works of $[36,37]$.

The values of the characteristic viscosities for the fully-ionized $[\eta]_{f i}$ and fully nonionized $[\eta]_{f n}$ states are calculated by extrapolation for zero abscissa. It is obvious that the ratio of these quantities will characterize the change in the volume of the coil macromolecule at the changes of polyion dissociation degree from 0 to 1 . Then the quantity of:

$$
\alpha=\left(\frac{[\eta]_{f i}}{[\eta]_{f n}}\right)^{\frac{1}{3}},
$$

will characterize the increase in the radius of the coil in the process of the polyelectrolyte swelling. All the calculated parameters for aqueous and mixed solvents show that the characteristic viscosity for a fully-ionized polymer decreases substantially with the elongation of the side alkyls. This is obviously connected with the hydrophobous interactions stabilizing a compact structure of the macromolecule. The consequence of this is the reduction of swelling parameter $\alpha$.

The value of the true characteristic viscosity at an infinitely large ionic strength of the solution has been obtained by isoionic dilutions method. The constancy of the ionic strength of the solution in the process of dilution results in a linear dependence of the reduced viscosity on the polymer concentration (Fig. 2). This makes it possible to determine the characteristic viscosity at a given ionic strength of the solution $[\eta]_{I i}$ as well as characteristic viscosity at the infinite ionic strength $[\eta]_{\infty}$ using the Fuoss-Strauss equation.

Based on the above experimental data, we attempted to determine some macromolecular parameters of synthesized ionenes, and also to estimate the change in nonelectrostatic interactions during PE solutions dilution with the use of empirical constants. The structure of the polymers obtained makes it possible to consider them as semirigid macromolecules and to determine the length of the statistical segment and the hydrodynamic radius of the macroion. 


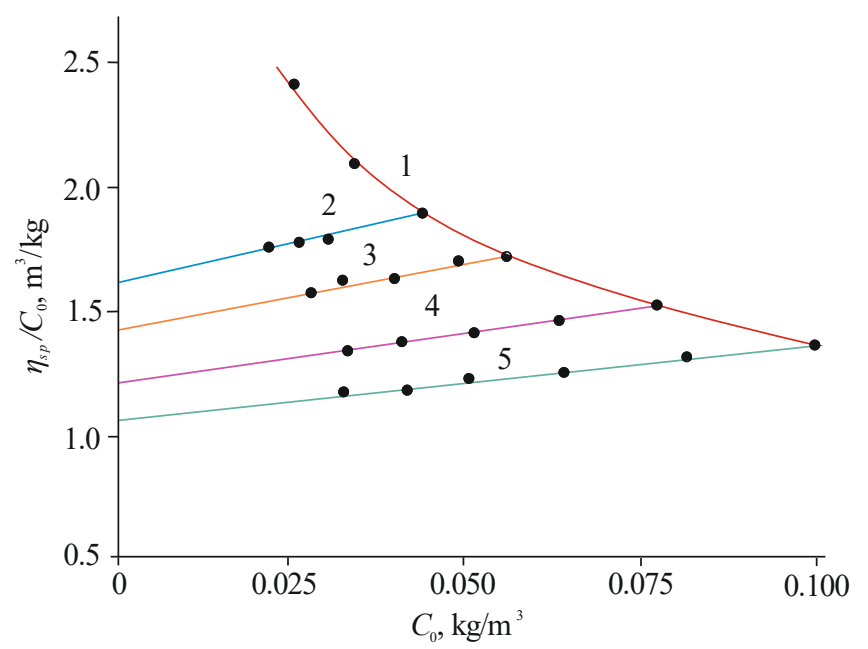

Fig. 2. Dependence of the reduced viscosity on the concentration for polyelectrolyte in water and in a salt brine: 1 - water; $2-5-$ in $\mathrm{KCl}$ solution with ionic strength, $\mathrm{mol} / \mathrm{m}^{3} ; 2-1.2 \cdot 10^{-3} ; 3-1.3 \cdot 10^{-3}$; $4-1.6 \cdot 10^{-3} ; 5-1.7 \cdot 10^{-3}$.

The values $[\eta]_{c}$ and $[\eta]_{\infty}$ are the characteristic viscosities at the infinite ionic strength. However, the value of $[\eta]_{c}$ characterizes the state of the polymer at its concentration in a solution tending to infinity, that is, under conditions of maximum non-electrostatic interactions, while $[\eta]_{\infty}$ value is determined by extrapolation to zero concentration. Thus, the ratio:

$$
\varphi_{\infty}=\frac{\eta_{c}}{\eta_{\infty}}
$$

will characterize the change in the volume of the coil macromolecule due to the hydrophobous bonds formation at infinite ionic strength. Then the ratio:

$$
\varphi_{I i}=\frac{\eta_{c}}{[\eta]_{I i}},
$$

will characterize non-electrostatic bonds destruction in the process of polyelectrolyte swelling in passing from an infinitely great to a fixed value of ionic strength. The calculated macromolecular parameters, as well as the values of $\varphi_{\infty}$ and $\varphi_{I i}$ show that an increase in the length of the side hydrocarbon radicals leads to intensification of non-electrostatic interactions and formation of more compact conformations.

This became a prerequisite for the use of watersoluble nitrogenated polymers, which include into the main chain the fragments of various organic acids, as the regulators of hydrochemical and hydrodynamic regimes in the process of GH production.

When adding this type of polymers in the concentration range of $10^{-3}-10^{-6} \mathrm{~g} / \mathrm{l}$, the reduced viscosity $\eta_{r} / C$ becomes negative, that is, the viscosity of the system is lower than the standard viscosity of water. The abnormal character of the aqueous solutions viscosity of the polymers presented leads to a change in the rate of hydrate formation processes. The degree of this influence is determined by the chemical structure and the molecular weight of the polymers.

The studies have been carried out in the laboratory conditions on the influence of five polymers on the hydrochemical and hydrodynamic regimes of aqueous systems (hereinafter polymers are represented by sequence numbers from 1 to 5 ). 
The experiment was carried out according to the methodology described in the work of [34]. Each of five polymers were added at concentrations of: $0.01 ; 0.05 ; 0.1 \mathrm{~mol} / \mathrm{m}^{3}$. Analysis of polymers influencing the process of methane hydrate formation was determined by the moles number of methane in the $\mathrm{GH}$ as well as according to the rate of formation. The analysis of obtained data shows that at all concentrations for polymers No. 1, 2, 3 and at concentrations of $0.05 \mathrm{~mol} / \mathrm{m}^{3}$ for polymers No. 4 and 5 , the concentration of gaseous methane is above the control point. The rate of the hydrate formation process compared to a control point at concentrations of $0.1 \mathrm{~mol} / \mathrm{m}^{3}$ for all polymers, and for polymer No. 4 at concentrations of $0.05 \mathrm{~mol} / \mathrm{m}^{3}-$ by $120-150 \%$. The dependence is presented in Fig. 3.

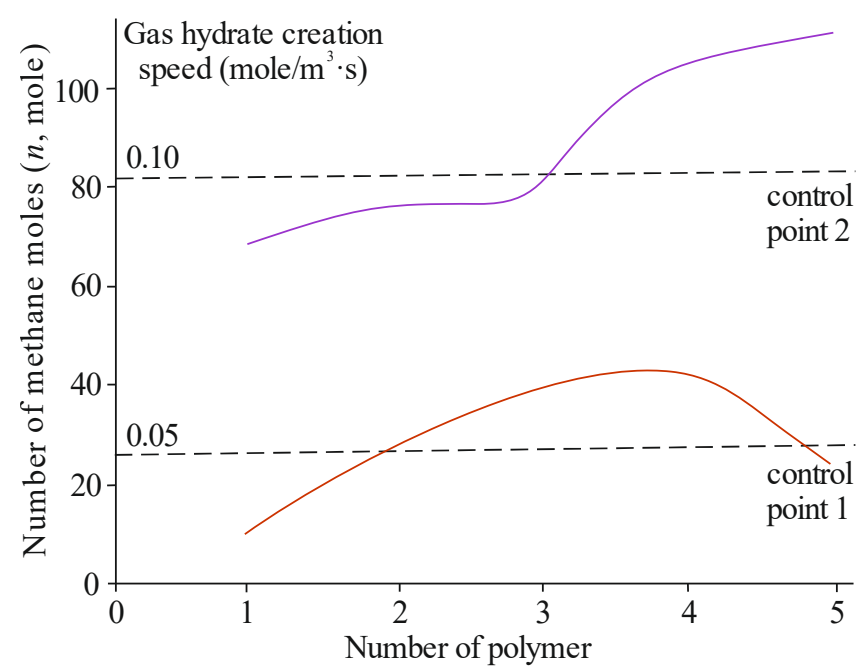

Fig. 3. Dependence of the amount of methane retention ( $n$, mole) in GH (1); dependence of the rate of $\mathrm{GH}$ formation in the PE presence at a polymer concentration of $0.01 \mathrm{~kg} / \mathrm{m}^{3}(2)$.

It was found out in experimental industrial installations that the rate of methane gas hydrate formation during the experiment ranged from 0.02 to $0.16 \mathrm{~mol} /\left(\mathrm{m}^{3} \cdot \mathrm{s}\right)$. The average values of this parameter indicate that for polymer No. 2 at its concentration of $0.1 \mathrm{~mol} / \mathrm{m}^{3}$ and No. 4 at a concentration of $0.01 \mathrm{~mol} / \mathrm{m}^{3}$, they exceed the control point value by $1.4-$ 1.5 times. The concentration of hydrogen ions during the experiment varied within the range of $\mathrm{pH}=8-9$.

It should be noted that the coefficient of this parameter variation ranges from 1.7 for polymer No. 4 at a concentration of $0.1 \mathrm{~mol} / \mathrm{m}^{3}$ to 4 at a concentration of $0.01 \mathrm{~mol} / \mathrm{m}^{3}$. It was 2.5 in the control series. It is of interest that the coefficient for methane variation is much higher, it ranges from 12.5 for control to 36.8 for polymer No. 4 at a concentration of $0.1 \mathrm{~mol} / \mathrm{m}^{3}$.

The rate of $\mathrm{GH}$ formation at the beginning of the experiment was low (1.9$\left.5.0 \mathrm{~mol} /\left(\mathrm{m}^{3} \cdot \mathrm{s}\right)\right)$, and after a certain time it increased by $2-17$ times, and, what is more, in the control point the increase was by 6 times. After one day, an increase in the rate of GH formation was observed for all polymers, except for control where it has decreased by $30 \%$.

The dynamics of the rate of methane hydrate formation in the presence of PE is presented in Fig. 4. 


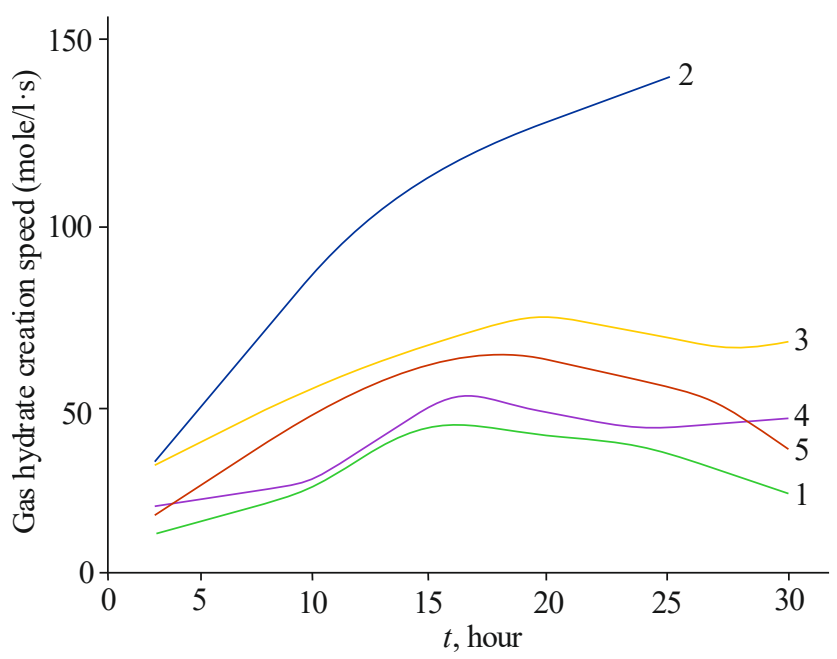

Fig. 4. Dynamics of the rate change in the methane hydrates formation: 1 -control; 2 -polymer No. 2 with a concentration of $0.05 \mathrm{~mol} / \mathrm{m}^{3} ; 3$ - polymer No. 1 with a concentration $0.1 \mathrm{~mol} / \mathrm{m}^{3} ; 4$ - polymer No. 5 with a concentration of $0.1 \mathrm{~mol} / \mathrm{m}^{3} ; 5$ - polymer No. 3 with a concentration of $0.05 \mathrm{~mol} / \mathrm{m}^{3}$.

\section{Conclusions}

It has been established on the basis of conducted experiments, that the studied polyelectrolytes (PEs) have a "retention" ability with respect to methane in water during the hydrate formation process, and also the $\mathrm{pH}$ media stabilization occurs.

The formation of GH occurs as a result of the macromolecules binding under the influence of gaseous methane and some other chemical additives that contribute to the increase in the number of gaseous methane moles, due to the exchange processes between the polymer matrix and watersoluble salts, and also in the change of the water system hydrodynamics.

Taking into account the peculiarities of $\mathrm{PE}$ solutions under the condition of temperature or $\mathrm{pH}$ change, and adding of chemical additives (salts), the coacervation phenomenon takes place, as a result of which the system is divided into two phases, which leads to the formation of a spatial grid. As a result, an increase in the rate of GH formation was observed from 2 to 17 times, depending on the PE structure, its concentration and the reaction time.

The mechanism of this process is associated with a spontaneous, uncontrolled change in the PE solutions viscosity. As a result of changes in the hydrodynamic properties of water, an increase in the amount of gaseous methane in the GH is observed up to $36.8 \mathrm{~mol}$ per a mole of water at a PE concentration of $0.1 \mathrm{~mol} / \mathrm{m}^{3}$.

The presented results were obtained in the framework of the complex implementation of research projects "Development of scientific principles of phase transformations of technogenic and natural gas hydrates and creation of the newest technologies of their extraction" (State registration No. 0115U002294) and "Scientific substantiation and development of energy saving and low waste technologies of hydrocarbon and mineral raw materials extraction" (State registration No. 0116U008041).

\section{References}

1. Mykhailov, V. (2016). Prospection and estimation of unconventional hydrocarbon deposits in Ukraine. Visnyk of Taras Shevchenko National University of Kyiv. Geology, 2(73), 38-45. https://doi.org/10.17721/1728-2713.73.06 
2. Samoilov, V.V. (2017). Planning of the industrial and hydrogeological research at the final stage of hydrocarbon deposits development. Visnyk of V.N Karazin Kharkiv National University Series Geology Geography Ecology, (46), 45-49.

3. Naumko, I., Kurovets', I., Zubyk, M., Batsevych, N., Sakhno, B., \& Chepusenko, P. (2017). Hydrocarbon compounds and plausible mechanism of gas generation in "shale" gas prospective Silurian deposits of Lviv paleozoic depression. Geodynamics, 1(22), 26-41. https://doi.org/10.23939/jgd2017.01.026

4. Petlovanyi, M.V., Lozynskyi, V.H., Saik, P.B., \& Sai, K.S. (2018). Modern experience of lowcoal seams underground mining in Ukraine. International Journal of Mining Science and Technology, 1-7. https://doi.org/10.1016/j.ijmst.2018.05.014

5. Bondarenko, V., Tabachenko, M., \& Wachowicz, J. (2010). Possibility of production complex of sufficient gasses in Ukraine. New Techniques and Technologies in Mining - Proceedings of the School of Underground Mining, 113-119. https://doi.org/10.1201/b11329-19

6. Saik, P., Petlovanyi, M., Lozynskyi, V., Sai, K., \& Merzlikin, A. (2018). Innovative approach to the integrated use of energy resources of underground coal gasification. Solid State Phenomena, (277), 221-231. https://doi.org/10.4028/www.scientific.net/ssp.277.221

7. Bondarenko, V., Lozynskyi, V., Sai, K., \& Anikushyna, K. (2015). An overview and prospectives of practical application of the biomass gasification technology in Ukraine. New Developments in Mining Engineering 2015: Theoretical and Practical Solutions of Mineral Resources Mining, 27-32. https://doi.org/10.1201/b19901-6

8. Pedchenko, M., Pedchenko, L., Nesterenko, T., \& Dyczko, A. (2018). Technological solutions for the realization of NGH-technology for gas transportation and storage in gas hydrate form. Solid State Phenomena, (277), 123-136. https://doi.org/10.4028/www.scientific.net/ssp.277.123

9. Bondarenko, V.I., Kharin, Ye.N., Antoshchenko, N.I., \& Gasyuk, R.L. (2013). Basic scientific positions of forecast of the dynamics of methane release when mining the gas bearing coal seams. Naukovyi Visnyk Natsionalnoho Hirnychoho Universytetu, (5), 24-30.

10. Bondarenko, V., Kovalevska, I., Astafiev, D., \& Malova, O. (2018). Examination of phase transition of mine methane to gas hydrates and their sudden failure - Percy Bridgman's effect. Solid State Phenomena, (277), 137-146. https://doi.org/10.4028/www.scientific.net/ssp.277.137

11. Pedchenko, L., Niemchenko, K., Pedchenko, N., \& Pedchenko, M. (2018). Use of alternative energy sources to improve the efficiency of natural gas hydrate technology for gas offshore deposits transportation. Mining of Mineral Deposits, 12(2), 122-131. https://doi.org/10.15407/mining12.02.122

12. Bondarenko, V., Sai, K., Prokopenko, K., \& Zhuravlov, D. (2018). Thermodynamic and geomechanical processes research in the development of gas hydrate deposits in the conditions of the Black Sea. Mining of Mineral Deposits, 12(2), 104-115. https://doi.org/10.15407/mining12.02.104

13. Bondarenko, V.I., \& Sai, K.S. (2018). Process pattern of heterogeneous gas hydrate deposits dissociation. Naukovyi Visnyk Natsionalnoho Hirnychoho Universytetu, (2), 21-28. https://doi.org/10.29202/nvngu/2018-2/4

14. Melnikov, V., \& Gennadinik, V. (2018). Cryodiversity: the world of cold on the Earth and in the solar system. Philosophy and Cosmology, (20), 43-54. https://doi.org/10.29202/phil-cosm/20/4

15. Mohebbi, V., \& Behbahani, R.M. (2014). Experimental study on gas hydrate formation from natural gas mixture. Journal of Natural Gas Science and Engineering, (18), 47-52. https://doi.org/10.1016/j.jngse.2014.01.016

16. Hanushevych, K., \& Srivastava, V. (2017). Coalbed methane: places of origin, perspectives of extraction, alternative methods of transportation with the use of gas hydrate and nanotechnologies. Mining of Mineral Deposits, 11(3), 23-34. https://doi.org/10.15407/mining11.03.023

17. Bondarenko, V., Svietkina, O., \& Sai, K. (2017). Study of the formation mechanism of gas hydrates of methane in the presence of surface-active substances. Eastern-European Journal of Enterprise Technologies, 5(6(89)), 48-55. https://doi.org/10.15587/1729-4061.2017.112313

18. Farhang, F. (2014). Kinetics of the formation of $\mathrm{CO}_{2}$ hydrates in the presence of sodium halides and hydrophobic fumed silica nanoparticles. $\mathrm{PhD}$ Thesis. Queensland: The University of Queensland. https://doi.org/10.14264/uql.2014.385 
19. Ganji, H., Manteghian, M., \& Rahimi Mofrad, H. (2007). Effect of mixed compounds on methane hydrate formation and dissociation rates and storage capacity. Fuel Processing Technology, 88(9), 891-895. https://doi.org/10.1016/j.fuproc.2007.04.010

20. Najibi, H., Mirzaee Shayegan, M., \& Heidary, H. (2015). Experimental investigation of methane hydrate formation in the presence of copper oxide nanoparticles and SDS. Journal of Natural Gas Science and Engineering, (23), 315-323. https://doi.org/10.1016/j.jngse.2015.02.009

21. Brown, T. D., \& Taylor, C. E. (2013). Rapid gas hydrate formation process. Patent No. 8354565, USA.

22. Kumar, A., Bhattacharjee, G., Kulkarni, B. D., \& Kumar, R. (2015). Role of surfactants in promoting gas hydrate formation. Industrial \& Engineering Chemistry Research, 54(49), 12217 12232. https://doi.org/10.1021/acs.iecr.5b03476

23. Dholabhai, P.D., Kalogerakis, N., \& Bishnoi, P.R. (1993). Kinetics of methane hydrate formation in aqueous electrolyte solutions. The Canadian Journal of Chemical Engineering, 71(1), 68-74. https://doi.org/10.1002/cjce.5450710110

24. Kalacheva, L.P., Rozhin, I.I., \& Fedorova, A.F. (2016). Izuchenie zavisimosti processov obrazovaniya i razlozheniya gidratov prirodnogo gaza ot himicheskoy prirody rastvorov elektrolitov, imitiruyushchih plastovye flyuidy. Mezhdunarodniy Zhurnal Prikladnyh $i$ Fundamental'nyh Issledovaniy, (8-4), 565-569.

25. Kalacheva, L.P., \& Rozhin, I.I. (2017). The influence of the chloride-calcium-type water composition on the properties of natural gas hydrates. Neftegazovaya Geologiya. Teoriya $i$ Praktika, 12(3). https://doi.org/10.17353/2070-5379/25 2017

26. Lang, X., Fan, S., \& Wang, Y. (2010). Intensification of methane and hydrogen storage in clathrate hydrate and future prospect. Journal of Natural Gas Chemistry, 19(3), 203-209. https://doi.org/10.1016/s1003-9953(09)60079-7

27. Holzammer, C., Finckenstein, A., Will, S., \& Braeuer, A.S. (2016). How sodium chloride salt inhibits the formation of $\mathrm{CO}_{2}$ gas hydrates. The Journal of Physical Chemistry B, 120(9), 24522459. https://doi.org/10.1021/acs.jpcb.5b12487

28. Fan, S.-S., \& Guo, T.-M. (1999). Hydrate formation of $\mathrm{CO}_{2}$-rich binary and quaternary gas mixtures in aqueous sodium chloride solutions. Journal of Chemical \& Engineering Data, 44(4), 829-832. https://doi.org/10.1021/je990011b

29. Guo T.-M., \& Qiu, J.-H. (2002). Kinetic of methane hydrate formation in pure water and ingibitor containing systems. Chinese Journal of Chemical Engineering, 10(3), 490-497.

30. Svietkina, O. (2013). Receipt of coagulant of water treatment from radio-active elements. Annual Scientific-Technical Collection - Mining of Mineral Deposits 2013, 227-230. https://doi.org/10.1201/b16354-42

31. Svietkin, Yu.V., Riabenko, V.V., Volkov, M.F., \& Varlan, K.E. (1984). Sposob stymulyrovanyia rosta zooplanktona. Patent No. 1137603, USSR.

32. Manzhai, V.N., Konovalov, K.B., \& Kazarian, M.A. (2017). Model povedeniya makromolekul v turbulentnom potoke i eye analiticheskiye sledstviya. Kratkiye Soobshcheniya po Fizike FIAN, (12), 3-6.

33. Ovchynnikov, M., Ganushevych, K., \& Sai, K. (2013). Methodology of gas hydrates formation from gaseous mixtures of various compositions. Annual Scientific-Technical Collection - Mining of Mineral Deposits 2013, 203-205. https://doi.org/10.1201/b16354-37

34. Bondarenko, V., Svietkina, O., \& Sai, K. (2018). Effect of mechanoactivated hemical additives on the process of gas hydrate formation. Eastern-European Journal of Enterprise Technologies, 1(6(91)), 17-26. https://doi.org/10.15587/1729-4061.2018.123885

35. Svetkina, Ye.Yu. (2013). Intensification of concentration process through minerals vibroactivation. Naukovyi Visnyk Natsionalnoho Hirnychoho Universytetu, (2), 38-43.

36. Fuoss, R.M. (1948). Viscosity function for polyelectrolytes. Journal of Polymer Science, 3(4), 603-604. https://doi.org/10.1002/pol.1948.120030414

37. Yuan, L., Dougherty, T.J., \& Stivala, S.S. (1972). A semi-empirical approach to the viscosities of polyelectrolyte solutions. Journal of Polymer Science Part A-2: Polymer Physics, 10(1), 171-189. https://doi.org/10.1002/pol.1972.160100113 